\title{
Surface Reading: An Introduction
}

\author{
Reading "The Way We Read Now"
}

The title of this special issue raises many questions. To begin with, who are "we"? Although Representations is a multidisciplinary journal, this issue's contributors and editors constitute a relatively homogeneous group of scholars who received doctoral degrees in either English or comparative literature after 1983. Our shared training delimits what we mean and don't mean by the term "read." As literary critics, we were trained to equate reading with interpretation: with assigning a meaning to a text or set of texts. As scholars formed in the era of interdisciplinarity, we take for granted that the texts we read and interpret include canonical and noncanonical literary works. We also feel licensed to study objects other than literary ones, using paradigms drawn from anthropology, history, and political theory, which themselves borrowed from literary criticism an emphasis on close reading and interpretation after the linguistic turn of the 1970s.

One factor enabling exchanges between disciplines in the 1970s and 1980s was the acceptance of psychoanalysis and Marxism as metalanguages. It was not just any idea of interpretation that circulated among the disciplines, but a specific type that took meaning to be hidden, repressed, deep, and in need of detection and disclosure by an interpreter. This "way" of interpreting went by the name of "symptomatic reading." We were trained in symptomatic reading, became attached to the power it gave to the act of interpreting, and find it hard to let go of the belief that texts and their readers have an unconscious.

So much for the way we read. What about "now"? In the last decade or so, we have been drawn to modes of reading that attend to the surfaces of

\footnotetext{
AB STRACT In the text-based disciplines, psychoanalysis and Marxism have had a major influence on how we read, and this has been expressed most consistently in the practice of symptomatic reading, a mode of interpretation that assumes that a text's truest meaning lies in what it does not say, describes textual surfaces as superfluous, and seeks to unmask hidden meanings. For symptomatic readers, texts possess meanings that are veiled, latent, all but absent if it were not for their irrepressible and recurring symptoms. Noting the recent trend away from ideological demystification, this essay proposes various modes of "surface reading" that together strive to accurately depict the truth to which a text bears witness. Surface reading broadens the scope of critique to include the kinds of interpretive activity that seek to understand the complexity of literary surfaces-surfaces that have been rendered invisible by symptomatic reading. / REPRESENTATIONS 108. Fall 2009 () The Regents of the University of California. ISSN 0734-6018, electronic ISSN 1533-855X, pages 1-21. All rights reserved. Direct requests for permission to photocopy or reproduce article content to the University of California Press at http://www. ucpressjournals.com/reprintinfo.asp. DOI:10.1525/ rep.2009.108.1.1.
} 
texts rather than plumb their depths. Perhaps this is because, at the end of the first decade of the twenty-first century, so much seems to be on the surface. "If everything were transparent, then no ideology would be possible, and no domination either," wrote Fredric Jameson in 1981, explaining why interpretation could never operate on the assumption that "the text means just what it says." The assumption that domination can only do its work when veiled, which may once have sounded almost paranoid, now has a nostalgic, even utopian ring to it. Those of us who cut our intellectual teeth on deconstruction, ideology critique, and the hermeneutics of suspicion have often found those demystifying protocols superfluous in an era when images of torture at Abu Ghraib and elsewhere were immediately circulated on the internet; the real-time coverage of Hurricane Katrina showed in ways that required little explication the state's abandonment of its African American citizens; and many people instantly recognized as lies political statements such as "mission accomplished." Eight years of the Bush regime may have hammered home the point that not all situations require the subtle ingenuity associated with symptomatic reading, and they may also have inspired us to imagine that alongside nascent fascism there might be better ways of thinking and being simply there for the taking, in both the past and the present. ${ }^{3}$ We find ourselves the heirs of Michel Foucault, skeptical about the very possibility of radical freedom and dubious that literature or its criticism can explain our oppression or provide the keys to our liberation. Where it had become common for literary scholars to equate their work with political activism, the disasters and triumphs of the last decade have shown that literary criticism alone is not sufficient to effect change. This in turn raises the question of why literary criticism matters if it is not political activism by another name, a question to which we return in the last section of this essay.

We have chosen our title for its resonance but are aware of the many readers and ways of reading that our contributors do not discuss at all, some of which our co-editors address in the afterword. "The Way We Read Now" calls to mind the title of Anthony Trollope's 1875 novel The Way We Live Now, echoed in recent books by Amanda Anderson (The Way We Argue Now) and Elaine Freedgood (in the coda to The Ideas in Things, entitled "Victorian Thing Culture and the Way We Read Now"). ${ }^{4}$ As a rubric, the phrase announces that we plan to perform a self-assessment, to survey the present-the deictic "now" carrying with it a note of urgency. It connotes change, the sense that now we do things a bit differently than they did back then. These essays also incorporate a site-specific "now" and "then," since the majority were first delivered at a 2008 conference jointly sponsored by Columbia University and New York University, which in turn emerged from a 2006 American Comparative Literature Association seminar convened to mark the twentyfifth anniversary of Fredric Jameson's publication of The Political Unconscious

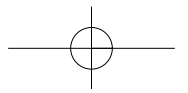


(1981), the book that popularized symptomatic reading among U.S. literary critics. The 2008 conference invited speakers to reflect on the current place of symptomatic reading, but in asking our contributors to expand their talks into essays, we set a somewhat different agenda, requesting that they articulate what alternatives to symptomatic reading currently shape their work, and how those alternatives might pose new ways of reading.

These essays represent neither a polemic against nor a postmortem of symptomatic reading. Our contributors trace nascent practices in the textbased disciplines, some of which evolve from symptomatic reading, some of which break from it. The "way" of our title should not be construed as a unitary mode or a pilgrimage to a single point, but as a road branching in multiple directions, like Jorge Luis Borges's garden of forking paths. It would be inaccurate, however, to call this issue "the ways we read now," because these articles demonstrate significant overlap among our contributors. To that extent, a different literary allusion is also apt for picturing how these articles are related, that of Swann's way, which initially appears separate from the Guermantes way but turns out to be connected to it at key points.

\section{Symptomatic Reading}

All of the contributors to this volume are responding to a particular notion of interpretation that came to be known as symptomatic reading. Broadly speaking, this practice encompasses an interpretive method that argues that the most interesting aspect of a text is what it represses, and that, as Fredric Jameson argued, interpretation should therefore seek "a latent meaning behind a manifest one" (60). The interpreter "rewrite[s] the surface categories of a text in the stronger language of a more fundamental interpretive code" (60) and reveals truths that "remain unrealized in the surface of the text" (48). As the letter of invitation to the 2008 conference put it, symptomatic reading asserts that "what a text means lies in what it does not say, which can then be used to rewrite the text in terms of a master code. By disclosing the absent cause that structures the text's inclusions and exclusions, the critic restores to the surface the deep history that the text represses." 5

When symptomatic readers focus on elements present in the text, they construe them as symbolic of something latent or concealed; for example, a queer symptomatic reading might interpret the closet, or ghosts, as surface signs of the deep truth of a homosexuality that cannot be overtly depicted. Symptomatic readings also often locate outright absences, gaps, and ellipses in texts, and then ask what those absences mean, what forces create them, and how they signify the questions that motivate the text, but that the text itself cannot articulate. ${ }^{6}$ Symptomatic reading thus often conflates three 
pairs of oppositions: present/absent, manifest/latent, and surface/depth. Strictly speaking, these are not compatible sets of terms. What is absent is simply not there; what is latent is present but invisible, unrecognized either because it is concealed or because it is undeveloped; what is deep is fully present and thus theoretically visible, but is positioned so far down, in, or back relative to a viewer, or is so completely covered by an opaque surface, that it can only be detected by an extreme degree of penetration or insight. The different connotations of manifest and surface are especially significant. The surface is associated with the superficial and deceptive, with what can be perceived without close examination and, implicitly, would turn out to be false upon closer scrutiny. The manifest has more positive connotations, as what is truthful, obvious, and clearly revealed.

The notion underlying all forms of symptomatic reading, that the most significant truths are not immediately apprehensible and may be veiled or invisible, has a very long history. Umberto Eco traces it back to the Gnostics in the second century CE, who, in contrast to Greek philosophers who defined reason as noncontradiction, posited truth as secret, deep, and mysterious, and language as inadequate to meaning. ${ }^{7}$ Eco might also have noted, however, the equally Greek roots of the idea that truth does not lie in evidence directly available to the senses, since this was the point of Plato's parable of the cave, which influenced not only the Gnostics but also Christians such as Paul, and led to their emphasis on allegory. ${ }^{8}$ Symptomatic reading thus has links to what Eco calls the hermetic theory of interpretation: the idea that words "hide the untold" and the secret of meaning is its impossibility (39-40). The notion of truth as recessive was not limited, however, to ancient mystics; as Mary Crane explains in her contribution to this volume, the idea that meaning and verity must be deep and inaccessible to view was also promoted by a technique that had close ties to science: the development of perspective in early modern European painting.

The nineteenth-century roots of symptomatic reading lie with Marx's interest in ideology and the commodity and Freud's in the unconscious and dreams. ${ }^{9}$ In an important essay entitled "Clues: Roots of an Evidential Paradigm," Carlo Ginzburg noted that Freud was "accustomed to divine secret and concealed things from unconsidered or unnoticed details"; in psychoanalysis, "infinitesimal traces permit the comprehension of a deeper, otherwise unattainable reality." 10 Those traces are clues, symptoms, details on the surface that indicate the form and content of hidden depths to the trained and intuitive interpreter. In Freud and Philosophy: An Essay on Interpretation (1970), Paul Ricoeur showed how Freud's model of interpretation was particularly suited to symbolic language, which he defined as any form of language "where another meaning is both given and hidden in an immediate meaning." Ricoeur defined the symbolic function as "to mean something

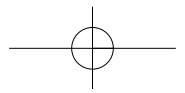


other than what is said," and posited that "to interpret is to understand a double meaning." What he called a "hermeneutics of suspicion" in Freud described a method of understanding double meaning based not on the religious model of revealed meaning but on the demystification of illusion. ${ }^{11}$ This hermeneutics of suspicion became a general property of literary criticism even for those who did not adhere strictly to psychoanalysis.

The other set of critics invested in symptomatic reading were Marxists engaged with the writings of Louis Althusser. In Reading Capital (published in French in 1968, in English translation in 1970), Althusser unfolded a method of symptomatic reading that he found in Marx and used to read Marx, one that "divulges the undivulged event in the text it reads, and in the same movement relates it to a different text, present as a necessary absence in the first."12 For Althusser, symptomatic reading makes "lacunae perceptible" (86); it assumes that texts are shaped by questions they do not themselves pose and contain symptoms that help interpreters articulate those questions, which lie outside texts as their absent causes. Althusser dismissed "the religious phantasm of epiphanic transparency" (35), the theory of reading as one of logos, in which each part immediately expresses the whole and there is no split between manifest and latent meaning. Although Althusser equated religious reading with instantaneous transparency, his theory actually harkens back to the Gnostic concept of truth as too complex to describe, because he defined history as what could not be read in manifest discourse, as "the inaudible and illegible notation of the effects of a structure of structures" (17). This concept of truth as antilogos, as what cannot be immediately understood, also resonates with Jacques Derrida's critique of truth as presence.

In The Political Unconscious (1981), Fredric Jameson argued that only weak, descriptive, empirical, ideologically complicit readers attend to the surface of the text. In an affirmative version of symptomatic reading, Jameson insisted that the "strong" critic must rewrite narrative in terms of master codes, disclosing its status as ideology, as an imaginary resolution of real contradictions (13). Like Althusser, Jameson saw the text as shaped by absence, but unlike Althusser, Jameson saw only one absent cause, history itself, and insisted that interpretation should seek a repressed, mystified, latent meaning behind a manifest one (60). For Jameson, interpretation is "unmasking"; meaning is the allegorical difference between surface and depth; and the critic restores to the surface the history that the text represses (20). That restoration entails the "semantic enrichment and enlargement of the inert givens and materials of a particular text" (75, emphasis added). Jameson's image of the critic as wresting meaning from a resisting text or inserting it into a lifeless one had enormous influence in the United States, perhaps because it presented professional literary criticism as a strenuous and heroic 
endeavor, one more akin to activism and labor than to leisure, and therefore fully deserving of remuneration. ${ }^{13}$ The influence of Jameson's version of symptomatic reading can be felt in the centrality of two scholarly texts from the 1990s: Eve Kosofsky Sedgwick's Epistemology of the Closet (1991), which crystallized the emergent field of queer theory, and Toni Morrison's Playing in the Dark: Whiteness and the Literary Imagination (1992), which set forth an agenda for studying the structuring role of race in American literature. ${ }^{14}$ Both showed that one could read a text's silences, gaps, style, tone, and imagery as symptoms of the queerness or race absent only apparently from its pages.

\section{Symptomatic Reading Now}

In the course of meditating on the way we read now, and performing current ways of reading, our contributors situate their practices in relation to symptomatic reading, positing their interpretive method as a variation on, supplement to, or critique of it. Those who want to continue using some version of symptomatic reading differ from one another in the degree of their willingness to stay inside texts, in contrast to Jameson's practice of moving beyond the text and across several interpretive "horizons" to reach frameworks too vast and abstracted to achieve direct textual expression (75). Those who take the greatest distance from symptomatic reading do so either to be less resisting, masterful readers or as part of a larger project of attending to the material life of books and thus to the many things done to and by books that do not involve reading at all. Almost all our contributors also seize on the surface/depth distinction so central to symptomatic interpretation in order to articulate what is new about the way we read now.

Closest to Jameson is Mary Crane, whose essay, "Surface, Depth, and the Spatial Imaginary: A Cognitive Reading of The Political Unconscious," draws on cognitive science to interpret the metaphors of surface and depth that Jameson uses to describe symptomatic reading. For Jameson, the unconscious is a function of repression, but for Crane, as a cognitive reader, the unconscious consists simply of mental activities too rapid and too complex to be perceived. The differences between the cognitive and the psychoanalytic versions of the unconscious produce different ways of interpreting contradictions in texts. Jameson's notion of the "political unconscious" leads him to argue that history, the dialectical conflict between freedom and necessity, is the repressed cause that explains how a text imaginarily resolves contradictions that are themselves not readily visible. Crane, by contrast, sees textual contradictions as manifest rather than hidden, and caused by a combination of biological, cultural, temporal, and personal factors. Crane takes as her example

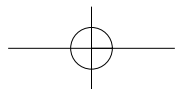


of textual contradiction The Political Unconscious itself, which she finds generates incompatible figurations of surface-as sediment, disguise, exoskeleton, and horizon. Those conflicting images point to underlying tensions in Jameson's theory: for example, between a reader who exposes a text's disguised truths, and a reader who actually produces those truths by secreting them like a carapace. Crane sees herself as performing a symptomatic reading on Jameson, since she argues that his conflicting images of the surface are signs of tacit contradictions in his theory that his propositional statements do not make explicit. She differs from Jameson, however, in explaining the form those contradictions take. Where Jameson reads contradictions as clues to the veiled operations of history, Crane understands an author's complex "spatial imaginary" as an effect of how cognition works.

For Margaret Cohen, in "Narratology in the Archive of Literature," Jameson is not sufficiently conscious of how much he takes genre for granted and thus limits himself to an overly restrictive canon. Cohen points out that symptomatic reading does not necessarily work equally well on all genres. Certain kinds of forgotten literature do not need to be decoded to be understood, and even the genres that Jameson subjects to decoding might be better understood if placed in a wider archive that includes nonliterary types of writing with which they have elements in common. Where Jameson presents his method as having the power to disclose the text's hidden depths, Cohen suggests that placing a text in its discursive contexts can illuminate textual features that are obvious but which critics have overlooked. Jameson uses the metaphor of the horizon to gesture toward what is beyond it, toward invisible levels of structural causality that only the critic can make visible within the grain of the text itself. Where Jameson's horizons recede infinitely, Cohen conceives of a horizon as a legible set of points one can use to navigate within a literary field. She describes a reading practice that uses large archives to reconstruct "the lost horizon of poetics," a horizon that defines the position of given texts and exists on the same plane or surface as the texts it explains. Turning to Joseph Conrad's Lord Jim, a text that figures prominently in The Political Unconscious, Cohen argues that, rather than locate the novel's value in its artful narrative poetics or sublime prose, we should situate it within the epistemological frames it shares with maritime writing: information, navigation, and practical reason.

In "Reading on the Left," Christopher Nealon offers a genealogy of the long-dominant idea, central to Jameson's notion of symptomatic reading, that the activist component of literature is a value added by the critic. Nealon observes that some critical theorists, such as Jean-Paul Sartre, believe that human action has priority over matter, while others, such as Jameson, Alain Badiou, Giorgio Agamben, and Antonio Negri and Michael Hardt, believe that matter has priority over human action on it. What this entire 
cohort shares, Nealon notes, is the conviction that they must determine which comes first. Literature, and poetry in particular, Nealon asserts, enacts the struggle between matter and human action rather than the victory of one over the other. Where symptomatic reading goes outside the text to find revolutionary subjects, or labor working on matter, Nealon finds the conflict between freedom and capitalism already present in poetry, which ceaselessly configures and reconfigures matter. If other theorists see politics as external to poetry, the depth that only the critic can bring to the surface, for Nealon the poem itself is where politics surface. The surface of the poem can thus contain its own hermeneutic; hermeneutics is not what critics do to the poem, since interpretation is happening in the poem. Using as his chief example a poem by Lisa Robertson, Nealon suggests that the very literariness of poetry emerges from bids for freedom internal to capitalism, not from revolutionary breaks with it. The left-leaning literary critic thus need not add theory to the text or gather texts that exemplify his theories; it is enough simply to register what the text itself is saying.

Where what Nealon finds internal to the text is its meaning, Leah Price immerses herself in books that direct us to go not only beyond interpretation but even beyond the act of reading itself. In "From The History of a Book to a 'History of the Book," Price breaks completely with symptomatic methods by suggesting that we do not, and need not, read books at all. Ironically, she locates the authority for that research program in books themselves, albeit ones that tell stories about how books are collected, displayed, and exchanged; used, abused, and reused; toted, shared, and preservedeverything but read. Historians of the book might discover a theory of their operations, Price proposes, in "it-narratives"-eighteenth- and nineteenthcentury fictional autobiographies "in which a thing traces its travels among a series of richer and poorer owners." It-narratives draw our attention to the literal surface of books, often missed in a hasty desire to plumb the depths of texts. But rather than teaching us simply to look at books in order to catalog their material characteristics, it-narratives teach us a new way to think about the classic opposition between the inert surface of things and the vibrant depths of persons. It-narratives about books do not simply reverse that opposition by personifying objects as subjects, Price shows, because they endow books with consciousness in order to have them recount histories that divert us from their interiority toward their superficial materiality, thus returning them to objecthood, but of an unusually vivid and significant kind.

Equally distant from Jameson is Anne Cheng, whose "Skins, Tattoos, and Susceptibility" urges that we replace suspicion and critical mastery with a susceptibility that could undo the dichotomy between subject and object. Noting that we can never separate surface from depth, that underneath surface

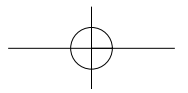


there is only more surface, Cheng advocates a "mutual pedagogy of erotics" in which the critic inhabits and is inhabited by what she studies, and embraces the loss of critical certainty and the gain in intimacy that result. Cheng sees a hermeneutics of suspicion as allied with a politics of identity, since what often motivates the reading of the surface as a symptom of hidden depths is the desire to restore and make visible the authenticity veiled by spectacle. She suggests that we replace the symptom, which depends on the contrast between surface and depth, with a constellation of multiple surfaces understood as concealing nothing. The essay itself does this by juxtaposing multiple representations of surfaces: Adolf Loos's writings on architectural cladding, the facade of a house he designed for Josephine Baker, and Baker's photographic presentation of her body, especially its skin. If critics fasten their attention on these surfaces, she argues, they can see how the modern and the primitivist exist on a single plane. The streamlined modernist surface associated with white masculine subjects merges with the black woman's skin, marked by ascriptions of nudity on the one hand and overadornment on the other. Though skin and the facade are marked by sex and race, they are thus also sites where racial and sexual distinctions break down.

\section{Surface Reading}

Surface looms large in the vocabulary of our contributors, but rarely do they mean the literal surface of texts: paper, binding, typography, the sounds of words read aloud. Nor do they construe surface as symptomatic readers often have-as a layer that conceals, as clothing does skin, or encloses, as a building's facade does its interior. Following the lead of our contributors, we take surface to mean what is evident, perceptible, apprehensible in texts; what is neither hidden nor hiding; what, in the geometrical sense, has length and breadth but no thickness, and therefore covers no depth. A surface is what insists on being looked at rather than what we must train ourselves to see through. ${ }^{15}$

Many types of reading, some quite old, some fairly new, might come under the rubric of "surface reading."

Surface as materiality. This kind of surface emerges primarily in two forms-in the history of the book and in cognitive reading. Bibliography attends to the literal surfaces of books themselves, making signs inseparable from their material supports. Histories of reading, publication, and circulation study books as things that link their producers, sellers, and users. Cognitive studies of literature attend to the material workings of the brain during the reading process and show how writing prompts readers to imitate what Elaine Scarry calls "the material conditions" that structure perception. ${ }^{16}$ 
Scarry shows that we can best produce mental images of depth and solidity by picturing one surface passing in front of another, because surfaces are easier to imagine than three-dimensional objects (10-12). The verbal arts, Scarry points out, are often associated with immateriality because they are "counterfactual" and ask us to picture what does not exist, but they are also significantly "counterfictional," because they infuse our ordinarily pallid imaginings with vivacity (38). Crucial to this process are objects, such as flowers, that we can easily envision and that thus become "the tissue of the mental images themselves—not the thing pictured, but the [mental] surfaces on which the images will get made" (48).

Surface as the intricate verbal structure of literary language. This understanding of surface produces close readings that do not seek hidden meanings, but focus on unraveling what Samuel Otter, in a recent account of New Formalism, has called the "linguistic density" and "verbal complexity" of literary texts. ${ }^{17}$ This type of surface reading, as Otter shows, would move slowly, if at all, from text to context, from parsing meaning to interpreting significance. ${ }^{18}$ This valorization of surface reading as willed, sustained proximity to the text recalls the aims of New Criticism, which insisted that the key to understanding a text's meaning lay within the text itself, particularly in its formal properties. Formalisms new and old argue against the traditional association of the surface with what is too simple to merit notice. As I. A. Richards pointed out, though such criticism "is very largely . . . an exercise in navigation" it still requires great skill. Since most readers have trouble construing the sensuous form and literal sense of poetry, simply paraphrasing a text or understanding its verbal meaning is a demanding "craft." 19

Embrace of the surface as an affective and ethical stance. Such an embrace involves accepting texts, deferring to them instead of mastering or using them as objects, and refuses the depth model of truth, which dismisses surfaces as inessential and deceptive. An early and influential statement of this approach was Susan Sontag's “Against Interpretation” (1966), which argued that interpreters do not disclose the text's true meaning but alter it. Instead of saying, "Look, don't you see that X is really—or, really means-A?" Sontag admonished, the critic of a work should "show it is what it is, even that it is what it is, rather than ... show what it means." Sontag's manifesto against the model of interpretation drawn from Freud and Marx refused the notion that meaning and content define the work of art and proposed that we set aside the theory of mimesis in favor of the experience of art in its "pure, untranslatable, sensuous immediacy," a stance that she also called an "erotics of art." ${ }^{20}$ Such an erotics can take the form of attending to the text, or to one's affective responses to it. Other versions of receptiveness and fidelity to the

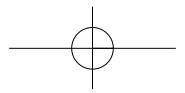


text's surface, as opposed to suspicious and aggressive attacks on its concealed depths, include Eve Kosofsky Sedgwick's “reparative reading” (discussed in the afterword to this issue), Timothy Bewes's "reading with the grain," and Jane Gallop's meditation on the ethics of close reading. ${ }^{21}$

To these we would add three other ways of doing surface reading that deeply interest us and that we hope will generate more discussion:

Attention to surface as a practice of critical description. This focus assumes that texts can reveal their own truths because texts mediate themselves; what we think theory brings to texts (form, structure, meaning) is already present in them. Description sees no need to translate the text into a theoretical or historical metalanguage in order to make the text meaningful. The purpose of criticism is thus a relatively modest one: to indicate what the text says about itself. Though we would not endorse Paul de Man's insistence on the "void that separates" poetic intent from reality, we remain intrigued by his observation that poetry is the "foreknowledge" of criticism, and that the interpreter therefore "discloses poetry for what it is" and articulates "what was already there in full light." 22 Similarly, Joel Fineman's Shakespeare's Perjured Eye argued that the traditional questions for criticism of the sonnets are already questions in the sonnets themselves; there is no need for a critical metalanguage to explain the sonnets because, as Aaron Kunin has recently observed, "the poems provide the most accurate description of their own operations." ${ }^{23}$ Here, depth is not to be found outside the text or beneath its surface (as its context, horizon, unconscious, or history); rather, depth is continuous with surface and is thus an effect of immanence.

Surface as the location of patterns that exist within and across texts. This notion includes narratology, thematic criticism, genre criticism, and discourse analysis. Symptomatic reading looks for patterns in order to break free of and reach beyond them to a deep truth too abstract to be visible or even locatable in a single text. Jameson thus urges interpreters to sketch the ideological rectangles that structure texts only in order to move toward what lies outside them. Surface readers, by contrast, find value in the rectangles themselves and locate narrative structures and abstract patterns on the surface, as aggregates of what is manifest in multiple texts as cognitively latent but semantically continuous with an individual text's presented meaning. In this type of surface reading, the critic becomes an anatomist breaking down texts or discourses into their components, or a taxonomist arranging and categorizing texts into larger groups. The anatomist and taxonomist rearrange texts into new forms but nonetheless attend to what is present rather than privilege what is absent. Examples of this kind of work include Clifford 
Siskin's demonstration that large-scale shifts in how literature defines reality coincide with epochal changes in media history, and Marc Angenot's study of "social discourse," in which he looks at everything published in France in a particular year in order to chart "a global typology of the prevailing sayable." ${ }^{24}$ Unconvinced that literature differs significantly from other kinds of writing, Angenot places literary surfaces on the same plane as "social discourse," defined as "the total network of meaning." 25 For Angenot, what defines ideology is its dispersal, and to understand it we must chart its extent as a commonplace worldview, not expose its falsity.

Surface as literal meaning. What Sharon Marcus has called "just reading" accounts for what is in the text "without construing presence as absence or affirmation as negation." ${ }^{26}$ Her example is female friendship in Victorian novels, which has often been read as a cover story for an otherwise unspeakable desire between women. Because critics assume that novels ending in marriage eliminate lesbian desire, they have also assumed that courtship plots exile female friendship to the narrative margins. In fact, Marcus shows, female friends rarely lose their centrality in novels with marriage plots, but critics have overlooked this out of an insistence on reading female friendship as something other than it is. Taking friendship in novels to signify friendship is thus not mere tautology; it highlights something true and visible on the text's surface that symptomatic reading had ironically rendered invisible. Similarly, Benjamin Kahan argues that, rather than interpret celibacy as repressed homosexuality, we adopt a "depthless hermeneutic" that would take celibacy as "the 'absence' of sex that it is." 27 Ann Stoler, in Along the Archival Grain, looks at imperial violence that was never hidden, and attends to the colonial state's interests in family life as a genuine preoccupation, not as "metaphors for something else."28

Other examples suggest an emerging interest in literal readings that take texts at face value. In his study of rumor in the archive, Stephen Best reads first-person testimony by Caribbean slaves who believed that the British monarch had freed them, viewing their words neither as evidence irredeemably corrupted by the sovereign power that extracted them, nor as verbatim speech through which we can recover subjects lost to history. Those words are, rather, exactly what they appear to be: "impossible speech" that oscillates between loyalty and insurgency, speech and paraphrase, fact and prophecy, confession and coercion, and in that sense reflects back to us the deeply felt uncertainty of the enslaved. Attention to the rumors on the surface of the archive challenges our conception of the latter as a repository of latent voices and "hidden transcripts," and requires that we reconsider whether the story of slavery can ever be narrated "from

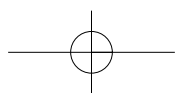


below" if our aim is to register what is inaccessible in the voice of the enslaved. ${ }^{29}$ Elisa Tamarkin similarly reads the American love of hierarchy, caste, and British traditions as meaning what it said. Unlike cultural historians who have read Anglophilia symptomatically, as a "guilty conscience that will not own [the egalitarian democracy] it has fought to gain," Tamarkin takes Anglophilia literally, as a statement of American national character that comprises attachment to deference as well as allegiance to independence. ${ }^{30}$

These understandings of what one can learn from surfaces resonate with a rarely cited statement Foucault made about his relationship to archives: rather than dig for "relations that are secret, hidden, more silent or deeper than . . consciousness," he described himself as seeking "to define the relations on the very surface of discourse" and "to make visible what is invisible only because it's too much on the surface of things." 31 Just reading sees ghosts as presences, not absences, and lets ghosts be ghosts, instead of saying what they are ghosts of.

\section{Freedom in Attentiveness}

If criticism is not the excavation of hidden truths, what can it add to our experience of texts? Can surface reading be anything other than a tacit endorsement of the status quo, the academic version of resignation's latest mantra, "It is what it is"? These questions are especially urgent because many of our most powerful critical models see criticism as a practice of freedom by locating autonomy, self-reflexiveness, detachment, and liberatory potential either in the artwork itself or in the valiant labor of the critic. In the former case, a measure of heroism is attributed to the artwork due to its autonomy from ideology; the latter makes the critic a hero who performs interpretive feats of demystification. The surface readers in this volume place noticeably less faith than many other critics in the heroic qualities of art, and they understand their critical activity as something other than wresting truths from the hidden depths of resisting texts. We feel it is important, therefore, to situate this volume in relation to dominant tendencies and to significant emergent moments within recent literary criticism that position themselves in relation to the two poles of critical freedom.

First, the dominant trends. One of the most emphatic recent articulations of the notion that freedom lies in aesthetic objects and aesthetic play can be found in the broad field styled as "New Formalist." As Marjorie Levinson describes in her recent review essay on the movement, a common assumption in much New Formalist work is that we do not need to criticize artworks, because they contain their own "critical (and self-critical) agency." 
New Formalists characterize the task of the critic as restoring the artwork to its "original, compositional complexity," a position that corresponds by and large to the aims of the old New Criticism and distances itself from what it perceives as attacks on literary form by New Historicism. ${ }^{32}$ In this essentially modernist view of art as a locus of critical autonomy, reading becomes what Levinson calls "learned submission," which is not as submissive as it sounds, because in submitting to the artwork, we come to share its freedom, by experiencing "the deep challenge that the artwork poses to ideology, or to the flattening, routinizing, absorptive effects associated with ideological regimes" (560). Immersion in texts frees us from the apathy and instrumentality of capitalism by allowing us to bathe in the artwork's disinterested purposelessness.

As Levinson rightly observes, the New Formalist view of the artwork's sovereignty over itself, its autonomy from ideology, largely ignores a materialist criticism that sees the artwork's freedom more dialectically, as an expression of struggles with its historical conditions and limits. This tradition is perhaps best represented by the writings of Theodor Adorno, whose essay "Commitment" proclaims that the office of art is to resist "solely through artistic form, the course of the world, which continues to hold a pistol to the heads of human beings." 33 On the one hand, the artwork's claim to autonomy stems from its bid to detach itself from empirical reality, but that detachment is never complete: "There is no content, no formal category of the literary work that does not, however unrecognizably transformed and unawarely, derive from the empirical reality from which it has escaped" (90). On the other hand, the very bid to escape from empirical reality, no matter how inevitably incomplete, makes the form of art inseparable from a dream of freedom in which the artwork's authors and critics can participate. "As pure artifacts, products, works of art, even literary ones, are instructions for the praxis they refrain from: the production of life lived as it ought to be" (93-94). Not surprisingly, then, Adorno elsewhere suggests the desirability of a mimetic relation between critics and their objects. As he wrote in his essay on the essay form, "nothing can be interpreted out of something that is not interpreted into it at the same time," and he adds a bit later, "thought's depth depends on how deeply it penetrates its object, not on the extent to which it reduces it to something else." ${ }^{34}$ Adorno thus advocates an immersive mode of reading that does not need to assert its distance and difference from its object. As Nealon observes in his essay for this volume, if we understand literary texts already to be "documents in the history of human struggles to be free," we can then "allow ourselves to imagine a mimetic relation between literature and criticism" without worrying that in doing so we are blunting our critical edge.

Equally interested in freedom, but locating it elsewhere, are those critics who believe that the text is a mystification and that the critic must therefore

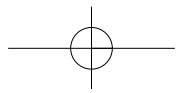


distance himself from it by adopting a point of view at variance with its optic. For this kind of critic, freedom emerges from an agon with the ideological text. There is perhaps no stronger advocate for this position than the Jameson of The Political Unconscious, who posits the Marxist critic as heroic in his or her own right, wrestling to free the truth hidden in the depths of the text. This vision accentuates the agency of the critic by using the violent imagery to which Mary Crane draws our attention, citing Jameson's description of the critic who penetrates a text's protective exoskeleton in an effort to retrieve "'a whole historical ideology that must be drawn, massy and dripping, up into the light before the text can be considered to have been read." "35 To the extent that authors are associated with freedom, Jameson posits the critic as the real author; the critic does not literally produce the text, but does produce whatever in it is related to truth. In this sense, Jameson is not only doing what E. D. Hirsch called usurping the place of the author (5); he is also more daringly associating the power of the critic with that of the God of biblical hermeneutics, who can transcend the blinkered point of view of humankind. Although Jameson notes that Augustine's Christian philosophy of history "can no longer be particularly binding on us" (18), and although Jameson differentiates his method of allegorical reading from Augustine's, he himself notes in passing the similarities between his totalizing Hegelian Marxism and Augustine's drive to read all texts in terms of Christian truth $(12,285)$. The structural similarities between Jameson's and Augustine's visions are in fact quite numerous. When Jameson writes that "the human adventure is one" (19), "a single vast unfinished plot" (20), he seeks to return to human life a unity that Augustine found only in God. Just as historical facts have only limited validity for Augustine, whose master code was Christianity, non-Marxist codes have only "sectoral validity" for Jameson, who overtly takes as his mission the task of rewriting texts in terms of a master code (10). Similarly, "always historicize" is a transhistorical imperative whose temporality matches the eternity Augustine ascribed to God. Where Augustine viewed God as the best author, Jameson sees the critic as the best author, and it is Jameson's transcendent faith in his critical values that allows him to insist, contra the poststructuralist critics whom he debates in his first chapter, "On Interpretation," that we must interpret texts and posit their meanings (58). Though Jameson distances himself from deconstructionists in this regard, his foundational belief in Marxism corresponds to their foundational belief in antifoundationalism, a belief that poses an irreconcilable contradiction for their thought.

At our most speculative and exploratory, we want to ask what it might mean to stay close to our objects of study, without citing as our reason for doing so a belief that those objects encapsulate freedom. We pose this question, in part, out of a sense of political realism about the revolutionary 
capacities of both texts and critics, and doubts about whether we could ever attain the heightened perspicacity that would allow us to see fully beyond ideology. We also detect in current criticism a skepticism about the very project of freedom, or about any kind of transcendent value we might use to justify intellectual work. A variety of critical styles in the second half of the twentieth century were marked by a utopian strain and a striving for redemption. Sontag subscribed to the "cult of art," Jameson expressed the divine aspirations of revolutionary critics, and those pursuing various forms of identity politics (feminism, queer studies, critical race studies) believed in the authority imbedded in particular subject positions. Across these various styles, the project of freedom came to be associated with what Christopher Nealon calls a "comportment"; he points out that for long it seemed to be the mandated task of either the artwork or the critic's theories about it to provide a finite array of stances from among which we had to choose "the one that will count as resistant, or subversive." 36 This appears to be less the case now if we take our contributors as at all representative. All seem to be relatively neutral about their objects of study, which they tend less to evaluate than to describe, and which they situate in landscapes neither utopian nor dystopian. Cohen is interested in the world of work and information that unfolds on ships, but stops short of the suggestion that we generalize from life at sea to life itself; Nealon does not take his central poet to task for her interest in fashion and other phenomena that mimic the antic pace of the commodity's life and death in capitalism; Cheng recognizes that Baker's composition of herself as modern was inseparable from her objectification of herself as primitive.

Surface reading, which strives to describe texts accurately, might easily be dismissed as politically quietist, too willing to accept things as they are. We want to reclaim from this tradition the accent on immersion in texts (without paranoia or suspicion about their merit or value), for we understand that attentiveness to the artwork as itself a kind of freedom. This strikes an ideal expressed most succinctly by Charles Altieri: "an ideal of being able not to worry about performing the self so that one can pursue potentials within the range of ongoing practices that are blocked by worries about identity and authenticity ... [a freedom to be able] to enjoy what and where one is without having to produce any supplemental claims that promise some "significance' not immediately evident." 37 To some ears this might sound like a desire to be free from having a political agenda that determines in advance how we interpret texts, and in some respects it is exactly that. We think, however, that a true openness to all the potentials made available by texts is also prerequisite to an attentiveness that does not reduce them to instrumental means to an end and is the best way to say anything accurate and true about them. Criticism that valorizes the freedom of the critic has often assumed that an adversarial relation to the object of criticism is the only way for the

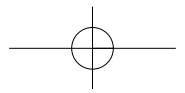


critic to free himself from the text's deceptive, ideological surface and uncover the truth that the text conceals. We want to suggest that, in relinquishing the freedom dream that accompanies the work of demystification, we might be groping toward some equally valuable, if less glamorous, states of mind.

This brings us to two emergent styles of doing literary criticism that resonate with the work in this volume-work that attends as much to the complexities of the critic's position as to those of the artwork, but seeks to occupy a paradoxical space of minimal critical agency.

We have in mind here, first, the recent turn toward computers, databases, and other forms of machine intelligence across a range of fields and practices, from book history to distant reading. Where the heroic critic corrects the text, a nonheroic critic might aim instead to correct for her critical subjectivity, by using machines to bypass it, in the hopes that doing so will produce more accurate knowledge about texts. Where the heroic text commands admiration of its unique features, computers can help us to find features that texts have in common in ways that our brains alone cannot. Computers are weak interpreters but potent describers, anatomizers, taxonomists. New media create new forms of knowledge, and digital modes of reading may be the inspiration for the hope that we could bypass the selectivity and evaluative energy that have been considered the hallmarks of good criticism, in order to attain what has almost become taboo in literary studies: objectivity, validity, truth. This might raise alarm that we are destroying existing rationales for studying the humanities: critical thinking, the uniqueness of art and culture, and the correspondingly distinctive ways that humanist disciplines study them. But to suggest that there might be ways of studying culture that would neither attack nor defend it is not to suggest that we abandon the study of culture altogether. It is to propose that rather than evaluate culture as masterworks of genius or documents of barbarism, we instead define what is unique about the disciplines that study culture as their interest in human artifacts, in contrast to the sciences, which focus on processes beyond our creation and control. To adopt some of the methods of science to the study of culture is not to say that scientists would be the better students of it, for scientists not only have little interest in studying cultural objects but also lack training in how to study them qualitatively. We are not envisioning a world in which computers replace literary critics but are curious about one in which we work with them to expand what we do.

We are thinking, second, of a critic like Anne-Lise François and her interest in a form of reading whose minimal agency would match that of certain textual moments of silence, deferral, acceptance, "complaisance without hope" (Open Secrets, xix). Taking its distance from the recuperative ethos of earlier styles that seemed capable of reading only "for hidden meanings and lost histories" (32), this type of criticism highlights "the agency of the act 
of bearing witness to the given" (35). Instead of turning to literature for models of how to overcome constraint, or for a right way to live under capital, or to register the difference between our critical freedom and the limits placed on others, we are interested in how to register the ways that constraints structure existence as much as breaking free of them does. The neutrality of description is thus not neutrality about the constraints themselves, which we may find ourselves moved to deplore, but neutrality about the existences entwined with them, which we would like to be able to recognize without judging. Just as many dismiss surface reading as obvious, but find themselves unable to sustain the slow pace, receptiveness, and fixed attention it requires, many readers might find that to refuse to celebrate or condemn their objects of study is, in practice, both difficult and discomfiting.

The essays that follow remind us that as much as our objects of study may conceal the structures that give rise to them, they also wear them on their sleeves; that the moments that arrest us in texts need not be considered symptoms, whose true cause exists on another plane of reality, but can themselves indicate important and overlooked truths. As Edgar Allan Poe's story "The Purloined Letter" continues to teach us, what lies in plain sight is worthy of attention but often eludes observation-especially by deeply suspicious detectives who look past the surface in order to root out what is underneath it. These essays also gesture toward a future for literary criticism that does not involve the untenable claim that we are always more free than those who produce the texts we study and that our insights and methods therefore have the power to confer freedom. At the same time, we would suggest that to begin to challenge the state of things, or the distortions of ideology, we must strive to produce undistorted, complete descriptions of them. Of course, one of the great questions of the last two centuries has been whether we can ever set aside our responses in order to produce undistorted accounts of things, since our responses are often unconscious and unknowable. Without fully answering that question, we believe that even if we cannot exhaustively explain what causes our responses, we can strive to describe them accurately, and that there is nothing inherently truthful or misleading about them. Sometimes our subjectivity will help us see a text more clearly, and sometimes it will not.

In closing, we want to underscore two points: that to see more clearly does not require that we plumb hidden depths and that producing accurate accounts of surfaces is not antithetical to critique; indeed, it may be, as Bruno Latour has recently suggested, the best way to move past the impasses created by what has become an excessive emphasis on ideological demystification. Referring to the ease with which conservatives question global warming by referring to it as a social construction rather than a scientific truth, he asks, "While we spent years trying to detect the real prejudices hidden

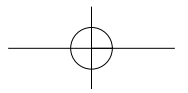


behind the appearance of objective statements, do we now have to reveal the real objective and incontrovertible facts hidden behind the illusion of prejudices?" 38 Latour reminds us that "the question was never to get away from facts but closer to them" (231) and notes that the critic "is not the one who debunks, but the one who assembles" (246). We began this essay by asserting the distance we would like to take from the type of symptomatic reading we inherited from psychoanalysis and Marxism, but in concluding we note that the work of assembly and the desire for a more complete view of reality are also aims of both schools of thought, which is one reason they remain central to the critics whose works we have assembled here. We hope these reflections on the way we read now give us a clearer view of the past and open up fertile paths of inquiry in the future.

\section{Notes}

We would like to thank the editorial board of Representations, which opened the journal's pages to us; the board members who met with us to discuss this issue; and our contributors, who responded so thoughtfully to our editorial suggestions. In addition, we would like to thank Ellis Avery, Amanda Claybaugh, Eric Ganther, Saidiya Hartman, Colleen Lye, Samuel Otter, Martin Puchner, Elisa Tamarkin, and our co-editors Emily Apter and Elaine Freedgood for their comments on drafts of this essay. Nicholas Dirks, Vice President for Arts and Sciences at Columbia University, made this publication possible by providing the crucial funding for the 2008 conference at which these papers were first presented; for their generous support of that conference, we also thank New York University's Humanities Initiative, its Office of the Dean of the Humanities, and all cosponsoring departments at Columbia and NYU.

1. Fredric Jameson, The Political Unconscious: Narrative as a Socially Symbolic Act (Ithaca, 1981), 61.

2. We note that there remain things that government powers go to extraordinary lengths to keep hidden, to keep as state secrets, "extraordinary rendition" being one of them. A hermeneutics of suspicion in which understanding requires a subtle reading of the situation thus remains readily pertinent to the work of critique. See, for example, Trevor Paglen, Blank Spots on the Map: The Dark Geography of the Pentagon's Secret World (New York, 2009).

3. We take this notion of what is there for the taking from Anne-Lise François, Open Secrets: The Literature of Uncounted Experience (Stanford, 2008), 10, who deploys it in a different historical context there than we do here.

4. Amanda Anderson, The Way We Argue Now: A Study in the Cultures of Theory (Princeton, 2006); Elaine Freedgood, The Ideas in Things: Fugitive Meaning in the Victorian Novel (Chicago, 2006).

5. Emily Apter, Elaine Freedgood, and Sharon Marcus, conference proposal, "The Way We Read Now: Symptomatic Reading and Its Aftermath," June 2007;

Surface Reading: An Introduction

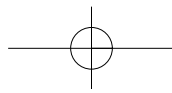


similar language appeared in the description of the March 2006 ACLA conference seminar "Symptomatic Reading and Its Discontents," organized and chaired by Sharon Marcus and convened in collaboration with Elaine Freedgood, John Plotz, and Leah Price.

6. As Ellen Rooney has put it, symptomatic reading produces "the absent question ... that the reading... establishes as unthinkable within the text's own problematic"; "Better Read Than Dead: Althusser and the Fetish of Ideology," Yale French Studies 88 (1995): 187.

7. Umberto Eco, "Interpretation and History," in Interpretation and Overinterpretation, ed. Stefan Collini (Cambridge, 1992), 31.

8. See Plato, The Republic, trans. G. M. A. Grube (Indianopolis, 1992), and Daniel Boyarin, A Radical Jew: Paul and the Politics of Identity (Berkeley, 1994).

9. On the interpretive homology between Marx's analysis of the commodity and Freud's analysis of dreams, see Slavoj Žižek, "How Did Marx Invent the Symptom?” Mapping Ideology, ed. Slavoj Žižek (New York, 1995), 296-331.

10. Carlo Ginzburg, "Clues: Roots of an Evidential Paradigm," in Clues, Myths, and the Historical Method, trans. John and Anne C. Tedeschi (Baltimore, 1989), 99, 101.

11. Paul Ricoeur, Freud and Philosophy: An Essay on Interpretation, trans. Denis Savage (New Haven, 1979), 7, 12, 8, 56.

12. Louis Althusser and Etienne Balibar, Reading Capital, trans. Ben Brewster (London, 1997), 28.

13. Mary Poovey argues that this account of reading as work originated with John Ruskin, who tended to cast meaning "not as self-evident because simply denoted by the author's words but as difficult and evasive." See her Genres of the Credit Economy: Mediating Value in Eighteenth- and Nineteenth-Century Britain (Chicago, 2007), 312-13.

14. Eve Kosofsky Sedgwick, Epistemology of the Closet (Berkeley, 1991); Toni Morrison, Playing in the Dark: Whiteness and the Literary Imagination (New York, 1992).

15. Margreta de Grazia and Peter Stallybrass use this locution (of looking at, rather than through) to discuss the importance of attending to errant textuality in "The Materiality of the Shakespearean Text," Shakespeare Quarterly 44 (Fall 1993): 255-83, 257.

16. Elaine Scarry, Dreaming by the Book (New York, 1999), 9.

17. Samuel Otter, "An Aesthetics in All Things," Representations 104 (Fall 2008): 116-25, 119. Otter's description of the literary-critical enterprise as an unraveling paraphrases Catherine Gallagher's observations regarding the legacies of New Criticism. See her "The History of Literary Criticism," in American Academic Culture in Transformation: Fifty Years, Four Disciplines, ed. Thomas Bender and Carl E. Schorske (Princeton, 1998), 151-72.

18. The distinction between meaning and significance belongs properly to E. D. Hirsch, for whom the former describes what an author means by a chosen sign sequence, whereas the latter names a relationship between that meaning "and a person, or a conception, or a situation, or indeed anything imaginable." E. D. Hirsch Jr., Validity in Interpretation (New Haven, 1967), 8.

19. I. A. Richards, Practical Criticism: A Study of Literary Judgment (1929; reprint, London, 1973), 312, 11.

20. Susan Sontag, "Against Interpretation," in Against Interpretation and Other Essays (New York, 1966), 6, 5, 14.

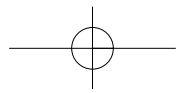


21. Eve Kosofsky Sedgwick, "Paranoid Reading and Reparative Reading, or, You're So Paranoid, You Probably Think This Essay Is About You," in Touching Feeling: Affect, Pedagogy, Perfomativity (Durham, 2003), 123-51; Timothy Bewes, "Reading with the Grain," unpublished manuscript, presented at 2006 ACLA seminar on symptomatic reading and later expanded; Jane Gallop, "The Ethics of Reading: Close Encounters," Journal of Curriculum Theorizing 16, no. 3 (2000): 7-18.

22. Paul de Man, Blindness and Insight (New York, 1971), 34, 31.

23. Joel Fineman, Shakespeare's Perjured Eye (Berkeley, 1986), 324 n.15; Aaron Kunin, "Shakespeare's Preservation Fantasy," PMLA 124 (January 2009): 95.

24. Clifford Siskin, "Textual Culture in the History of the Real," Textual Culture 2, no. 2 (Autumn 2007): 118-30; Marc Angenot, "Social Discourse Analysis: Outlines of a Research Project," Yale Journal of Criticism 17 (2004): 199-215, 200.

25. See Marc Angenot, Ce que l'on dit des Juifs en 1889. Antisémitisme et discours social (Saint-Denis, 1989), 177, translation ours.

26. Sharon Marcus, Between Women: Friendship, Desire, and Marriage in Victorian England (Princeton, 2007), 75.

27. Benjamin Kahan, “The Viper's Traffic-Knot': Celibacy and Queerness in the 'Late' Marianne Moore," GLQ 14, no. 4 (2008): 510, 512.

28. Ann Stoler, Along the Archival Grain: Epistemic Anxieties and Colonial Common Sense (Princeton, 2009), 63.

29. Stephen Best, "Rumor in the Archive," unpublished manuscript, presented at "The Way We Read Now: Symptomatic Reading and Its Aftermath," Columbia University and New York University, May 2008.

30. Elisa Tamarkin, Anglophilia: Deference, Devotion, and Antebellum America (Chicago, 2008), xxiv, xxvi-xxvii.

31. Foucault Live: Interviews, 1961-84, ed. Sylvère Lotringer, trans. John Johnston (New York, 1989), 57-58.

32. Marjorie Levinson, "What Is New Formalism?" PMLA 122, no. 2 (March 2007): $558-69,560$.

33. Theodor Adorno, "Commitment," in Notes to Literature: Volume Two, ed. Rolf Tiedemann, trans. Shierry Weber Nicholsen (New York, 1992), 80.

34. Theodor Adorno, "The Essay as Form," in Notes to Literature: Volume One, ed. Rolf Tiedemann, trans. Shierry Weber Nicholsen (New York, 1991), 11.

35. Margaret Crane, "Surface, Depth, and the Spatial Imaginary: A Cognitive Reading of The Political Unconscious," in this issue; citing Jameson, The Political Unconscious, 245.

36. Christopher Nealon, "Un-Militant Thinking," unpublished manuscript, delivered at "The Way We Read Now: Symptomatic Reading and Its Aftermath," Columbia University and New York University, May 2008.

37. Charles Altieri, "Cavell's Imperfect Perfectionism," in Ordinary Language Criticism: Literary Thinking After Cavell After Wittgenstein, ed. Kenneth Dauber and Walter Jost (Evanston, 2003), 216.

38. Bruno Latour, "Why Has Critique Run Out of Steam? From Matters of Fact to Matters of Concern," Critical Inquiry 30, no. 2 (Winter 2004): 227. 